\title{
DEEP Study: Indirect and out-of-pocket costs of Persistent Orofacial Pain
}

Breckons M, Shen, J, Bunga, J, Vale, L, Durham J.*

M. Breckons ${ }^{1}$, Research Associate

J. Shen ${ }^{1}$, Senior Research Associate

J. Bunga ${ }^{1}$, Health Economics Research Group Intern

L. Vale ${ }^{1}$, Health Foundation Chair in Health Economics

J.Durham ${ }^{1,2}$, Professor of Orofacial Pain

1 Health Economics Group

Institute of Health \& Society

The Baddiley-Clark Building

Richardson Road

Newcastle upon Tyne

NE2 4AX

*Corresponding author: Justin.Durham@ncl.ac.uk

Tel: +44 (0)1912087828

Fax: +44 (0) 1912086043

${ }^{2}$ Centre for Oral Health Research

School of Dental Sciences

Framlington Place

Newcastle University

NE2 4BW

UK

Abstract word count: 300

Total word count: 3156

Total number of tables: 5

Number of references: 33

Keywords: chronic pain, facial pain, healthcare utilization, cost analysis, graded chronic pain scale, quality-of-life 


\begin{abstract}
Persistent Orofacial Pain (POFP) is common and caused by a group of conditions affecting the face, head or mouth. Recent research has highlighted a problematic care pathway with high costs to the healthcare provider, but the financial impact on patients and employers is not understood. This study aimed to describe patient (out-of-pocket) and employer (indirect) costs of POFP and identify whether the dichotomized Graded Chronic Pain Scale (GCPS) was predictive of costs.
\end{abstract}

A cohort of 198 patients was recruited from primary and secondary care settings in the North-East of England and followed over a 24-month period. Patients completed GCPS and 'use of health services and productivity' questionnaires every 6 months and a 'time and travel questionnaire' at 14 months. Questionnaires examined the implications of healthcare utilisation on patients' everyday lives and personal finances. Time and travel costs were calculated and applied to use of services data to estimate out-of-pocket costs, while the human capital method and 'QQ method' (Quantity and Quality of work completed) were used to estimate absenteeism and presenteeism costs respectively.

Mean out-of-pocket costs were £333 (95\%Cl: 289 - 377) and indirect costs were £1242 (95\%Cl: 1014 - 1470) per person per six-month period (in 2017 pounds sterling).

Regression analyses indicated that over six months GCPS was predictive of both out-ofpocket costs (a difference of $£ 311$ between low and high GCPS per person per six-month period, 95\% Cl: £280-342; p< 0.01, 705 observations over 24 months) and indirect costs (a difference of $£ 2312$ per person per six-month period between low and high GCPS; $95 \% \mathrm{Cl}$ : $£ 1886-2737, p<0.01,352$ observations over 24 months).

This analysis highlights 'hidden' costs of POFP and supports the use of the dichotomized GCPS to identify patients at risk of higher impact and associated costs and thereby stratify care pathways and occupational health support appropriately.

Keywords: chronic pain, facial pain, healthcare utilization, cost analysis, graded chronic pain scale, quality-of-life 


\section{Introduction}

Persistent Orofacial Pain (POFP) refers to a group of conditions affecting the face and mouth and includes: temporomandibular disorders, burning mouth syndrome, persistent dentoalveolar pain, trigeminal neuralgia, and atypical facial pain (persistent idiopathic facial pain). A range of prevalence rates of POFP have been reported (Aggarwal et al. 2010; Goulet and Woda 2017; Horst et al. 2015; Macfarlane et al. 2001), and these figures, ranging from $5-14 \%$, are suggestive that POFP is relatively common.

Recent qualitative data from individuals experiencing POFP suggest problems with the existing care pathway (Breckons et al. 2017). This research describes how patients attend a large number of appointments with different healthcare professionals but fail to obtain effective diagnoses, treatment or referral for their pain. Research highlighting healthcare providers' perspectives on POFP corroborate these findings as they suggest difficulties diagnosing and treating POFP (Aggarwal et al. 2011a; Aggarwal et al. 2011b; Durham et al. 2007; Peters et al. 2015) in addition to service constraints including limited numbers of specialist services (Aggarwal et al. 2011a). Collectively these studies suggest a problematic care pathway from both provider and patient perspectives.

Recent data have outlined costs associated with POFP from a health service provider's perspective and suggested that pain related disability, as measured by the dichotomized Graded Chronic Pain Scale (Von Korff et al. 1992), is predictive of direct health service costs and thereby, as a proxy, of treatment need (Durham et al. 2016). These data have also suggested that health service costs are primarily driven by a high number of consultations.

Whilst research is limited, there is some suggestion that for pain conditions similar to POFP, such as headache, a large proportion of costs are associated with reduced productivity at work, so called "presenteeism" (Linde et al. 2012). This is in contrast to a persistent pain condition such as lower back pain for which indirect costs may be comprised of a larger proportion of absence-related costs, i.e. "absenteeism" (Juniper et al. 2009). To our knowledge, no research has examined costs of POFP from the perspective of patients or employers which are important from a health policy perspective in order to understand the potential implications to the wider economy. The aim of this study was, therefore, to describe the indirect and out-of-pocket costs of POFP and determine whether dichotomized GCPS status is predictive of either of these.

\section{Methods}

Ethical approval for the study was obtained via the local research ethics committee (National Research Ethics Service reference 12/YH/0338). The full protocol of the study is available in open access format (Durham et al. 2014).

\section{Sample and recruitment}

A sample size calculation indicated that 200 participants were needed $(\alpha=0.05)$ to detect a moderate effect size of 0.4 (Cohen 1988) between groups using 2-tailed inferential statistics with $80 \%$ power. This sample size also allowed us to examine up to 30 predictors of costs using regression analyses at a moderate effect size $(\alpha=0.05 ; \beta=0.8)$ (Green 1991). The dichotomised graded chronic pain scale was the predictor of interest, having demonstrated prognostic value (Von Korff et al. 1992), and been shown to be predictive of health service costs in POFP (Durham et al. 2016). Participants were recruited from primary care (community) dental ( $n=10$ dental practices) and medical practices ( $n=25$ medical practices), secondary care (hospital/specialist) from a range of departments (neurology, oral medicine, oral and maxillofacial surgery, and restorative dentistry) in North-East England, and through 
self-referral via healthcare and public advertisements. People were eligible for this study if they:

- had experienced orofacial pain for three months or more,

- screened positive using validated self-report screening instruments for

musculoskeletal, neuropathic or vascular origin of pain,

- were 18 or more years old

- $\quad$ were able to provide informed consent and communicate complex constructs in English.

The recruitment strategy was to recruit 240 patients in order to allow for an anticipated $20 \%$ attrition rate over the 2-year follow-up.

Recruiting clinicians returned a proforma upon receipt of which the study team contacted patients by telephone to conduct a standardised, validated screening questionnaire. This screening tool (Gonzalez et al. 2011; Hapak et al. 1994) classified the origin of patients' pain into: (i) musculoskeletal (ii) neuropathic/vascular (iii) combined. This screening method's sensitivity and specificity has been previously reported for this study: musculoskeletal (sensitivity, 63.1\%; specificity, 85.9\%), neuropathic/ vascular (sensitivity, 66.3\%; specificity, 96.8\%) (Durham et al. 2016). Upon positive screening patients were invited to participate in the study and the study team obtained written informed consent. Patients who screened negative were thanked for their time and did not take part in the study unless a specialist clinical diagnosis was available which indicated that the screening result was a false negative.

\section{Data collection}

Three instruments were used to collect data about out-of-pocket and indirect costs. These questionnaires are described here and examples are included in the Appendix (Figures 1 and 2):

1. Case report form (CRF): Upon entry into the study all participants completed a structured telephone interview with a trained interviewer at which they reported: demographic and socioeconomic details (education level, employment status, income, residential area); the details of their healthcare contacts and treatments received over the duration of their pain up to that point in time. Residential area was used to allocate an Index of Multiple Deprivation (IMD; official measure of deprivation in England (Department for Communities and Local Government 2015)).

2. Use of services and productivity questionnaire [USPQ] (Thompson et al. 2001) completed at Baseline, 6, 1218 and 24 months: This is a two part questionnaire. Part one collects data on use of health services over the past 6 months: participants were asked to report how many times they had visited a list of different types of Healthcare Professionals (HCPs), and to report any out-of-pocket expenditure on over the counter medication, prescription charges, NHS dental treatment, private treatment and any additional costs attributable to POFP. Part two collects data on participants' employment status, number of days contracted, and the number of days that individuals were either absent from ('absenteeism'), or attended ('presenteeism') work with pain in the previous 6 months. The quality and quantity method (QQ method) (Brouwer et al. 1999) and work attendance with health problems scale from the health and labour questionnaire (Van Roijen et al. 1996) were incorporated into the USPQ (Figure 1, Appendix). 
For the QQ method participants were asked to indicate on two numerical rating scales the quality and quantity of work performed while working with pain (anchored at 1 [Practically Nothing'/Very Poor Quality] and at 10 [Normal Quantity/Normal Quality]). The work attendance with health problems scale uses a list of six problems with a 4-point ordinal scale response indicating frequency (Appendix, Figure 3).

3. Time and travel questionnaire (Thompson et al. 2001) completed at 14 months: Participants were asked to report, for all the HCPs they had visited, the distance, duration and their usual mode of transport to appointments and provide additional information such as whether they were accompanied by a companion or required childcare. Participants were also asked what their activity would have been if they had not been attending a HCP (Figure 2, Appendix).

The Graded Chronic Pain Scale [GCPS] (Von Korff et al. 1992) was used to assess pain related disability at $0,6,12,18$ and 24 months. Its summary score allows classification on a five-point ordinal scale from Grade 0 (Low intensity, Low disability) to Grade IV (High Disability, Severely Limiting). A dichotomized GCPS score (High [IV-Ilb]; Low [Ila-0]) was then calculated from the five point ordinal scale using an algorithm developed by Dworkin et al (Dworkin et al. 2002).

\section{Data analysis}

Prior to data analysis, data were cross-checked by two researchers (MB \& JD) and cleaned in order to remove errors, inconsistencies or unfeasible responses. Costs collected over the two year study period were all converted into 2012 prices (the year the study started) within the analysis, adjusted for inflation using the Consumer Price Index (CPI), a measure of change in prices of goods and services over time from the Office for National Statistics (procedure described in detail in Figure 4, Appendix). The resulting final costs were then converted to the latest price year using the most recent CPI figure available and are presented in the paper in 2017 pounds sterling. Costs were calculated by time point and then all cost data were pooled from all time points thereby allowing calculation of a mean cost per six-month period over the entire study. Discounting of costs was not required as we were examining average costs for a 6-month period only.

\section{Patient Out-of-pocket costs}

Out-of-pocket costs were the sum of the following three categories:

(i) Treatment and assessment costs

These costs related to fees individuals had to pay directly including: prescription charges, NHS dental costs, private treatment costs and over the counter medication. Participants reported these costs directly at each time point in the USPQ and values reported are the sum of the reported costs.

(ii) Time and travel costs These consisted of travel costs to and from appointments (e.g. public transport, private vehicle, or taxi costs) and travel and appointment time costs (e.g. lost wages or leisure time). Data from the 'time and travel questionnaire' was used to calculate a unit cost per type of appointment for each patient (Figure 5, Appendix). Hourly and daily wages were calculated using annual salary information (from the CRF) and days worked per week (from USPQ). Standard UK values were used for mileage rates and leisure time (Figure 6, Appendix) (Douglas and Johnson 2004). This unit cost was then applied to the number of 
appointments reported at each time point in the USPQ. Companion costs (where reported) were calculated identically and added to the participant costs.

(iii) Additional costs

These consisted of any additional reported expenditure that patients attributed to their POFP.

\section{Indirect costs}

For the subsample of participants reporting being in employment, we estimated the cost to their employer due to absenteeism using the Human Capital method (Van den Hout 2010) that applies participant's daily wage to the length of time they reported being absent. Costs related to presenteeism were calculated using the $Q Q$ method (Brouwer et al. 1999), details of which are provided in the Appendix (Figure 7).

\section{Statistical procedures}

All analyses were performed using STATA 13 (version 13; StataCorp LP). Descriptive statistics were calculated to describe mean and standard deviation values of costs.

Parametric inferential statistical tests were used to examine the possible time effect on costs. Bootstrapping (bias-corrected accelerated method with 1000 repetitions) was used to produce confidence intervals around mean value. As appropriate for cost data with a skewed distribution (Julie and Simon 2004), generalised linear models (GLMs) using a log link function, were used to examine the relationship between dichotomised GCPS status and out-of-pocket costs and indirect costs, controlling for demographic and socioeconomic factors, including: age, gender, education level (no public examinations; secondary examinations; degree or higher), index of multiple deprivation ( $50 \%$ least deprived; $50 \%$ most deprived) and duration of pain at start of the study (less than 1 year, 1-4 years, 5 years or greater). Time point dummy variables were also included in the regression to control for any possible time effect.

The size of the sample varied by time point and dropout/non-response is described in detail in Figure 1. Participants were included in this analysis if they returned both the USPQ and GCPS questionnaires. Missing data rates for respondents were low; across the time points the mean level of missing data for participants was between 2 and $6 \%$. Missing data were imputed using UK reference costs and or mean/median imputation where appropriate (details and worked examples Appendix, Figure 8). This report follows the STROBE guidelines for reporting cohort studies (Von Elm et al. 2014) and the relevant points of the CHEERS checklist (Husereau et al. 2013).

\section{Results}

For the overall study 387 individuals were referred for screening and 279 agreed to be screened. Of those screened 268 screened positive and met inclusion criteria and 239 of these individuals agreed to participate (details of recruitment location in Table 1, Appendix). The consort diagram (Figure 1) demonstrates the flow of participants through the study. For this paper, patients were included in the analysis at a time point if they had returned GCPS and USPQ data.

\section{Out-of-pocket costs}

Table 1 demonstrates the sociodemographic details of the sample included in the analysis at each time point. The changing number of individuals at each time point represents those 
who dropped-out, most frequently by non-response. Within a six-month period, the cohort reported a mean of 9 (SD 12) healthcare appointments. Table 2 demonstrates their total outof-pocket costs per person per six-month period for these visits as well as treatment and assessment costs incurred due to POFP (Mean £333 [95\%Cl: 289; 377]).

The total number of observations in the GLM regression (Table 2, Appendix) was 705 over the 5 time-points due to missing sociodemographic data. The regression indicated that those with a high GCPS ( $\mathrm{n}=227$ ) had increased out-of-pocket costs; those with a low GCPS $(\mathrm{n}=478)$ had mean out-of-pocket costs of $£ 240(95 \% \mathrm{Cl} 230 ; 250)$ and those in the high GCPS had mean out-of-pocket costs of $£ 551$ (95\% Cl 522; 581); and the difference in cost between groups was a mean of $£ 311$ (95\% Cl: 280; 342 ; $P<0.01)$ per person per sixmonth period. Whilst out-of-pocket costs did not differ significantly between $\mathrm{M} 0$ and $\mathrm{M} 6$, at M12, M18 and M24 out-of-pocket costs were significantly less than baseline $(F(4,785)=$ 4.90; $p<0.01$ ) (Figure 9, Appendix).

\section{Indirect costs}

At each of the time points around half (range 48.5-51.7\%, Appendix Table 3 ) of the participants reported being employed. Those employed, reported missing a mean of 1.7 (SD $=5.9$ ) days over a six-month period due to their POFP. This absenteeism equated to an employer cost of $£ 174$ (95\% Cl: 113; 236) per person per six-month period (Table 4). Those employed reported attending work with pain for a mean of $34.6(S D=42.9)$ days per sixmonth period. The $Q Q$ method suggested a mean decrease over the 24 months of observations of $17.4 \%(S D=20.7)$ in the quantity (mean 8.3 out of 10 [SD=2.1]), and $16.9 \%$ $(S D=18.8)$ in the quality (8.3 out of 10 [SD=1.9]), of work completed whilst in pain. These reported losses were used to estimate mean employer costs of $£ 1068$ (95\% Cl: 849; 1287) per person per six-month period due to presenteeism. The most commonly reported problem facing individuals whilst at work was 'problems concentrating' $(73 \%)$ due to POFP followed by 'decision making' (59\%) (Appendix, Figure 3).

The total number of observations in the GLM regression over the 5 time-points (Table 4, Appendix) was 352 due to missing sociodemographic data. The regression demonstrated that those with a high GCPS status $(n=101)$ had higher indirect costs; those with a low GCPS ( $n=251)$ had mean indirect costs of $£ 681(95 \% \mathrm{Cl} 631 ; 730)$ and those in the high GCPS ( $n=101)$ had mean indirect costs of $£ 2992(95 \% \mathrm{Cl} 2575 ; 3410)$; the difference in costs between the groups was $£ 2312$ (95\% Cl: 1886; $2737 ; P<0.01)$ per person per sixmonth period. Although the employer costs did not differ significantly over the first four timepoints (Appendix, Figure 10), M24 patient costs were significantly less than M6 costs $(F(4,390)=3.42: p<0.01)$.

\section{Discussion}

This analysis builds on work examining costs of POFP (Durham et al. 2016) and suggests that in addition to health service costs, there are also considerable out-of-pocket and indirect costs to be considered that fall on patients, their families and employer. Research in other conditions has highlighted the burden on the individual caused by financial demands of a chronic condition (Piette et al. 2004). Additionally, our data highlight a need to ensure presenteeism is assessed as otherwise absenteeism taken in isolation may underestimate the impact of persistent pain conditions on the workforce. 
These data suggest that the GCPS may have predictive value in identifying those who are likely to incur high out-of-pocket and indirect costs and thus be at risk of the impact of these additional costs. This analysis also suggests that in addition to the potential of the dichotomized GCPS to predict higher healthcare costs it may be a useful screening tool for determining who is at risk of incurring the highest out-of-pocket costs and having their work affected by their pain. The most common problems affecting individuals whilst at work with POFP were difficulties concentrating and making decisions alongside having to work at a slower pace.

The GCPS represents a way to screen those who are in the greatest need of occupational health support whilst continuing ongoing management for their POFP. It may be possible then, as in other similar pain conditions such as migraine, to institute simple logistical, educational, or pacing interventions that will help improve the quality of work and work environment for those experiencing POFP thereby improving productivity and reducing the effect of presenteeism (Berry 2007; McLean 2009; Parker and Waltman 2012; VicenteHerrero et al. 2004). There are, however, no data currently available on what measures would be sensible to help those experiencing POFP whilst at work and this is an area for further research.

Our previous quantitative and qualitative research (Breckons et al. 2017; Durham et al. 2016) have highlighted the large number of appointments that individuals attend in an attempt to obtain a diagnosis and treatment for their POFP. This difficult and convoluted care pathway increases both the distress to the patient and cost to the health service. Data from the current study also demonstrate its wider economic impact. Durham et al have previously suggested a stratified system may offer advantages over the current system (Durham et al. 2016) and this study provides further support for the idea of such a pathway.

There are several limitations to this study: with regard to the size and selection of the cohort, we have recruited from a single region of the UK and therefore we do not know how generalizable our results are. Additionally, while we recruited people who had experienced POFP for varying lengths of time, given that the data suggested a possible temporal downward trend in both out-of-pocket and indirect costs it would be of further interest to investigate costs beyond the duration of the study to provide a clearer picture of longer term implications to patients and employers. While the level of missing data was generally low, as with all treatment of missing data, imputation and assumptions of questions being nonapplicable have the potential to under or overestimate costs. In addition, study dropout always has the potential to introduce selection bias.

In summary, POFP is known to have a profound and debilitating impact on people's lives and this paper has highlighted 'hidden' costs of the condition. Future work should focus on how care pathways can be designed to better meet the needs of patients. Given the high levels of presenteeism and the potential financial impact on employers further research on how people experiencing POFP can be supported at work is warranted.

\section{Author Contributions}

M. Breckons contributed to data acquisition, analysis and interpretation, drafted and critically revised the manuscript; J. Shen contributed to data analysis and interpretation, drafted and critically revised the manuscript; J. Bunga contributed to data analysis and interpretation and critically revised the manuscript; L. Vale contributed to conception, design, data analysis and interpretation and critically revised the manuscript; J. Durham contributed to conception, design, data acquisition, analysis and interpretation, drafted and critically revised the manuscript and secured funding for the study. All authors gave final approval and agree to be accountable for all aspects of the work. 


\section{Acknowledgements}

We thank the patients and health professionals who participated in this study and made it possible. We also thank the steering group members who have given very valuable advice at differing stages of the ongoing study.

This study and J.D. were funded by the National Institute for Health Research (NIHR;

Clinician Scientist Award NIHR-CS-011-003). The views expressed in this publication are those of the author(s) and not necessarily those of the National Health Service, the NIHR, or the Department of Health in the United Kingdom.

The authors declare no potential conflicts of interest with respect to the authorship and/or publication of this article. 


\section{References}

Aggarwal VR, Joughin A, Zakrzewska J, Appelbe P, Tickle M. 2011a. Dentists' preferences for diagnosis, management and referral of chronic oro-facial pain: Results from a national survey. Health Education Journal. 71(6):662-669.

Aggarwal VR, Joughin A, Zakrzewska JM, Crawford FJ, Tickle M. 2011b. Dentists' and specialists' knowledge of chronic orofacial pain: Results from a continuing professional development survey. Primary Dental Care. 18(1):41-44.

Aggarwal VR, Macfarlane GJ, Farragher TM, McBeth J. 2010. Risk factors for onset of chronic orofacial pain - results of the north cheshire oro-facial pain prospective population study. Pain. 149(2):354-359.

Berry PA. 2007. Migraine disorder: Workplace implications and solutions. AAOHN Journal. 55(2):5156.

Breckons M, Bissett SM, Exley C, Araujo-Soares V, Durham J. 2017. Care pathways in persistent orofacial pain: Qualitative evidence from the deep study. JDR Clinical \& Translational Research. 2(1):48-57.

Brouwer WBF, Koopmanschap MA, Rutten FFH. 1999. Productivity losses without absence: Measurement validation and empirical evidence. Health Policy. 48(1):13-27.

Cohen J. 1988. Statistical power analysis for the behavioral sciences. Lawrence Erlbaum.

Department for Communities and Local Government. 2015. The english index of multiple deprivation - 2015 guidance.

Douglas AJ, Johnson RL. 2004. The travel cost method and the economic value of leisure time. International Journal of Tourism Research. 6(5):365-374.

Durham J, Breckons M, Araujo-Soares V, Exley C, Steele J, Vale L. 2014. Developing effective and efficient care pathways in chronic pain: Deep study protocol. BMC oral health. 14(1):6.

Durham J, Exley C, Wassell R, Steele JG. 2007. 'Management is a black art'-professional ideologies with respect to temporomandibular disorders. British dental journal. 202(11):E29.

Durham J, Shen J, Breckons M, Steele JG, Araujo-Soares V, Exley C, Vale L. 2016. Healthcare cost and impact of persistent orofacial pain. Journal of dental research. 95(10):1147-1154.

Dworkin SF, Huggins KH, Wilson L, Mancl L, Turner J, Massoth D, LeResche L, Truelove E. 2002. A randomized clinical trial using research diagnostic criteria for temporomandibular disordersaxis ii to target clinic cases for a tailored self-care tmd treatment program. Journal of orofacial pain. 16(1).

Gonzalez YM, Schiffman E, Gordon SM, Seago B, Truelove EL, Slade G, Ohrbach R. 2011. Development of a brief and effective temporomandibular disorder pain screening questionnaire: Reliability and validity. The Journal of the American Dental Association. 142(10):1183-1191.

Goulet J-P, Woda A. 2017. Orofacial pain: Classification and road map to clinical phenotypes. Orofacial pain biomarkers. Springer. p. 3-20.

Green SB. 1991. How many subjects does it take to do a regression analysis. Multivariate behavioral research. 26(3):499-510.

Hapak L, Gordon A, Locker D, Shandling M, Mock D, Tenenbaum HC. 1994. Differentiation between musculoligamentous, dentoalveolar, and neurologically based craniofacial pain with a diagnostic questionnaire. Journal of orofacial pain. 8(4):357.

Horst OV, Cunha-Cruz J, Zhou L, Manning W, Mancl L, DeRouen TA. 2015. Prevalence of pain in the orofacial regions in patients visiting general dentists in the northwest practice-based research collaborative in evidence-based dentistry research network. The Journal of the American Dental Association. 146(10):721-728. e723.

Husereau D, Drummond M, Petrou S, Carswell C, Moher D, Greenberg D, Augustovski F, Briggs AH, Mauskopf J, Loder E. 2013. Consolidated health economic evaluation reporting standards (cheers) statement. Cost Effectiveness and Resource Allocation. 11(1):6. 
Julie B, Simon T. 2004. Multiple regression of cost data: Use of generalised linear models. Journal of Health Services Research \& Policy. 9(4):197-204.

Juniper M, Le TK, Mladsi D. 2009. The epidemiology, economic burden, and pharmacological treatment of chronic low back pain in france, germany, italy, spain and the uk: A literaturebased review. Expert opinion on pharmacotherapy. 10(16):2581-2592.

Linde M, Gustavsson A, Stovner LJ, Steiner TJ, Barré J, Katsarava Z, Lainez JM, Lampl C, Lantéri Minet M, Rastenyte D. 2012. The cost of headache disorders in europe: The eurolight project. European journal of neurology. 19(5):703-711.

Macfarlane TV, Glenny AM, Worthington HV. 2001. Systematic review of population-based epidemiological studies of oro-facial pain. Journal of dentistry. 29(7):451.

McLean A. 2009. Supporting individuals with migraine in the workplace. Work. 34(1):123-127.

Parker C, Waltman N. 2012. Reducing the frequency and severity of migraine headaches in the workplace: Implementing evidence-based interventions. Workplace health \& safety. 60(1):12-18.

Peters S, Goldthorpe J, McElroy C, King E, Javidi H, Tickle M, Aggarwal VR. 2015. Managing chronic orofacial pain: A qualitative study of patients', doctors', and dentists' experiences. Br J Health Psychol. 20(4):777-791.

Piette JD, Heisler M, Wagner TH. 2004. Problems paying out-of-pocket medication costs among older adults with diabetes. Diabetes Care. 27(2):384-391.

Thompson S, Wordsworth S, Costs UKWPoP. 2001. An annotated cost questionnaire for completion by patients. University of Aberdeen, Health Economics Research Unit.

Van den Hout WB. 2010. The value of productivity: Human-capital versus friction-cost method. Annals of the rheumatic diseases. 69(Suppl 1):i89-i91.

Van Roijen L, Essink-Bot M-L, Koopmanschap MA, Bonsel G, Rutten FFH. 1996. Labor and health status in economic evaluation of health care: The health and labor questionnaire. International journal of technology assessment in health care. 12(03):405-415.

Vicente-Herrero T, Burke TA, Laínez MJA. 2004. The impact of a worksite migraine intervention program on work productivity, productivity costs, and non-workplace impairment among spanish postal service employees from an employer perspective. Current medical research and opinion. 20(11):1805-1814.

Von Elm E, Altman DG, Egger M, Pocock SJ, Gøtzsche PC, Vandenbroucke JP, Strobe I. 2014. The strengthening the reporting of observational studies in epidemiology (strobe) statement: Guidelines for reporting observational studies. International Journal of Surgery. 12(12):14951499.

Von Korff M, Ormel J, Keefe FJ, Dworkin SF. 1992. Grading the severity of chronic pain. Pain. 50(2):133-149. 
Figure 1. Consort Diagram showing patient flow over the 2 year follow up period

40 excluded $^{1}$ :

20 failed to return consent

11 failed to meet inclusion

criteria

9 declined to participate after

screening positive

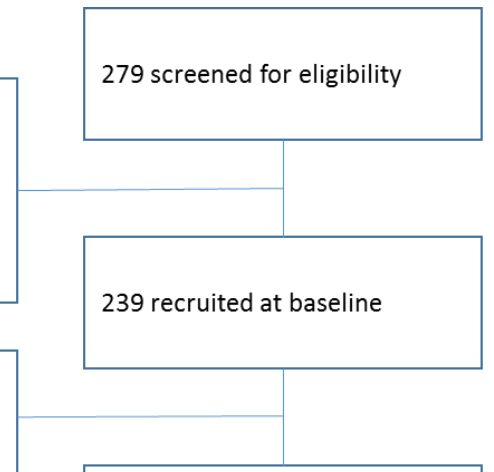

37 patients did not return $\mathrm{MO}$ questionnaires $^{2}$

0: CRF, USPQ \& GCPS

202 returned $\mathrm{MO}$ data ${ }^{3,4}$

(198 included in this analysis)

26 patients did not return $\mathrm{M} 6$ questionnaires 5

16 patients did not return $\mathrm{M} 12$ questionnaires ${ }^{6,7}$

19 patients did not return M14 questionnaire 8,9

M6: USPQ \& GCPS

175 returned $\mathrm{M} 6$ data

(172 included in this analysis)

\section{M12: USPQ \& GCPS}

159 returned $\mathrm{M} 12$ data

(155 included in this analysis)

5 patients did not return M18 questionnaires ${ }^{10}$

7 patients did not return $\mathrm{M} 24$ questionnaires ${ }^{11}$

M24: USPQ \& GCPS

132 returned $\mathrm{M} 24$ data

(129 included in this analysis)

${ }^{1}$ There was no significant difference in age, gender or origin of pain between positively screened patients who participated and those who declined $(P>0.05)$.

${ }^{2}$ There were no significant differences in gender, ethnicity, duration of pain or origin of pain between those dropping out and the 198 participants whose data was included in the study $(p>0.05)$. However those participating were significantly older than those who dropped out $(\mathrm{p}<0.01)$.

${ }^{3}$ One patient withdrew from the study at M18 and requested that their data be withdrawn.

${ }^{4}$ Data was not received from 3 participants at M0 who reported returning data but this was not received by the study team. These patients returned data at subsequent time points. 
${ }^{5}$ There was no significant difference between those dropping out at M6 and the M0 sample on the basis of: Age, Gender, Ethnicity, Duration of pain or Origin of pain ( $P>0.05)$.

${ }^{6}$ There was no significant difference between those dropping out at M12 and the M0 sample on the basis of: Age, Gender, Ethnicity or Origin of pain $(P>0.05)$ although those dropping out had a significantly longer duration of pain to those participating at baseline $(P<0.05)$.

${ }^{7}$ One of these patients went on to complete data at a further time point.

${ }^{8}$ There was no significant difference between those dropping out at M14 and the M0 sample on the basis of: Age, Gender, Ethnicity, Duration of pain or Origin of pain $(P>0.05)$.

${ }^{9}$ Three of these patients went on to return data at subsequent time points.

${ }^{10}$ There was no significant difference between those dropping out at M18 and the M0 sample on the basis of: Age, Gender, Duration of pain or Origin of pain ( $P>0.05)$, although those dropping out consisted of a greater proportion of a White British ethnic group than those participating at baseline $(\mathrm{P}<0.01)$.

${ }^{11}$ There was no significant difference between those dropping out at M24 and the M0 sample on the basis of: Age, Gender, Duration of pain or Origin of pain $(P>0.05)$, although those dropping out consisted of a greater proportion of a White British ethnic group than those participating at baseline $(\mathrm{P}<0.01)$. 
Table 1. Sociodemographic information of the sample analysed at each time point

\begin{tabular}{|c|c|c|c|c|c|c|}
\hline \multirow{2}{*}{$\begin{array}{l}\text { Sociodemographic } \\
\text { Characteristic }\end{array}$} & \multicolumn{6}{|c|}{ Time point } \\
\hline & $\begin{array}{l}\text { M0 } \\
(n=198)\end{array}$ & $\begin{array}{l}\text { M6 } \\
(n=172)\end{array}$ & $\begin{array}{l}\text { M12 } \\
(n=155)\end{array}$ & $\begin{array}{l}M 14 \\
(n=141)\end{array}$ & $\begin{array}{l}\text { M18 } \\
(n=136)\end{array}$ & $\begin{array}{l}\text { M24 } \\
(n=129)\end{array}$ \\
\hline Females, n (\%) & $160(80.8)$ & $139(80.8)$ & $127(81.9)$ & $113(80.1)$ & $110(80.9)$ & $106(80.9)$ \\
\hline Age, mean years (SD) & $51.8(16)$ & $52.3(15.6)$ & $53.0(14.9)$ & $53.2(14.8)$ & $53.7(14.7)$ & $53.5(14.6)$ \\
\hline \multicolumn{7}{|l|}{ Ethnic origin, $\mathbf{n}(\%)$} \\
\hline White, British & $158(79.8)$ & $137(79.7)$ & $122(78.7)$ & $107(75.9)$ & $104(76.5)$ & $100(77.5)$ \\
\hline $\begin{array}{l}\text { White, any other white } \\
\text { background }\end{array}$ & $1(0.5)$ & $1(0.6)$ & $0(0)$ & $1(0.7)$ & $0(0)$ & $0(0)$ \\
\hline $\begin{array}{l}\text { Black, black British, or } \\
\text { African }\end{array}$ & $1(0.5)$ & $1(0.6)$ & $1(0.7)$ & $1(0.7)$ & $1(0.7)$ & $1(0.8)$ \\
\hline Other, Chinese & $1(0.5)$ & $1(0.6)$ & $1(0.7)$ & $1(0.7)$ & $1(0.7)$ & $0(0)$ \\
\hline Other, not known & $4(2)$ & $3(1.7)$ & $3(1.9)$ & $3(2.1)$ & $3(2.2)$ & $3(2.3)$ \\
\hline Not provided & $7(3.5)$ & $6(3.5)$ & $5(3.2)$ & $6(4.3)$ & $5(3.7)$ & $4(3.1)$ \\
\hline Missing data & $26(13.0)$ & $23(13.4)$ & $23(14.8)$ & $22(15.6)$ & $22(16.2)$ & $21(16.3)$ \\
\hline \multicolumn{7}{|l|}{$\begin{array}{l}\text { Highest educational level } \\
\text { n (\%) }\end{array}$} \\
\hline $\begin{array}{l}\text { University, postgraduate } \\
\text { degree or diploma }\end{array}$ & $22(11.1)$ & $20(11.6)$ & $19(12.3)$ & $18(12.8)$ & $16(11.8)$ & $15(11.6)$ \\
\hline $\begin{array}{l}\text { University, undergraduate } \\
\text { degree or diploma }\end{array}$ & $54(27.3)$ & $47(27.3)$ & $42(27.1)$ & $38(27.0)$ & $38(27.9)$ & $37(28.7)$ \\
\hline Vocational qualifications & $43(21.7)$ & $38(22.1)$ & $35(22.6)$ & $30(21.3)$ & $28(20.6)$ & $29(22.5)$ \\
\hline $\begin{array}{l}\text { Secondary school public } \\
\text { examinations }\end{array}$ & $39(19.7)$ & $33(19.2)$ & $26(16.8)$ & $25(17.7)$ & $24(17.65)$ & $22(17.1)$ \\
\hline No public examinations & $23(11.62)$ & $19(11.1)$ & $18(11.6)$ & $16(11.4)$ & $16(11.8)$ & $14(10.9)$ \\
\hline Missing data & $17(8.6)$ & $15(8.7)$ & $15(9.7)$ & $14(9.9)$ & $14(10.3)$ & $12(9.3)$ \\
\hline \multicolumn{7}{|l|}{$\begin{array}{l}\text { IMD decile ranking of } \\
\text { home postcode, } n(\%)^{a}\end{array}$} \\
\hline $\begin{array}{l}9 \text { and } 10 \text { (least deprived } \\
\text { areas of the United } \\
\text { Kingdom) }\end{array}$ & $29(14.7)$ & $23(13.4)$ & $16(10.3)$ & $16(11.4)$ & $15(11.0)$ & $14(10.9)$ \\
\hline 7 and 8 & $39(19.7)$ & $31(18.0)$ & $26(16.8)$ & $27(19.1)$ & $26(19.1)$ & $26(20.2)$ \\
\hline 5 and 6 & $31(15.66)$ & $30(17.5)$ & $29(18.7)$ & $24(17.0)$ & $24(17.7)$ & $22(17.1)$ \\
\hline 3 and 4 & $44(22.2)$ & $39(22.7)$ & $37(23.9)$ & $32(22.7)$ & $32(23.5)$ & $30(23.3)$ \\
\hline $\begin{array}{l}1 \text { and } 2 \text { (most deprived } \\
\text { areas of the United } \\
\text { Kingdom }\end{array}$ & $52(26.3)$ & $48(27.9)$ & $45(29.3)$ & $40(28.4)$ & $37(27.21)$ & $36(27.9)$ \\
\hline Missing data & $3(1.5)$ & $1(0.6)$ & $2(1.3)$ & $2(1.42)$ & $2(1.5)$ & $1(0.8)$ \\
\hline \multicolumn{7}{|l|}{ Employment ${ }^{\mathrm{b}} \%$} \\
\hline Groups 1-3c & 59 & 54 & 52 & 48 & 45 & 46 \\
\hline Groups 4-6c & 39 & 35 & 26 & 23 & 23 & 22 \\
\hline Groups 7-9c & 18 & 17 & 17 & 15 & 15 & 13 \\
\hline Unemployed & 27 & 22 & 19 & 16 & 15 & 13 \\
\hline
\end{tabular}




\begin{tabular}{|l|l|l|l|l|l|l|}
\hline Retired & 44 & 35 & 33 & 33 & 32 & 29 \\
\hline Sick leave due to POPF & 2 & 2 & 2 & 2 & 2 & 2 \\
\hline Student & 5 & 3 & 2 & 2 & 2 & 2 \\
\hline Missing data & 4 & 4 & 4 & 2 & 2 & 2 \\
\hline
\end{tabular}

aThe Index of multiple deprivation describes relative deprivation in small geographical areas in England.

${ }^{\mathrm{b}}$ The number reporting employment differed between the initial case report form (CRF) and the data provided in the Use of Services and Productivity Questionnaire (USPQ). The above table is based on the CRF data as this contained further details about employment status but the analysis in this paper is based on USPQ data which represented the dynamic status of employment.

'Employment type was categorised using Major groups from the UK Office for National Statistics Standard Occupational Classification 2010. Groups are as follows: 1, Managers, directors and senior officials; 2, Professional occupations; 3, Associate professional and technical occupations; 4, Administrative and secretarial occupations; 5, Skilled trades occupations; 6, Caring, leisure and other service occupations; 7, Sales and customer service occupations; 8, Process, plant and machine operatives; 9, Elementary occupations. 
Table 2. Mean out-of-pocket costs in pounds sterling per 6 month period

\begin{tabular}{|l|l|l|l|}
\hline Time point & $\begin{array}{l}\text { Mean treatment and } \\
\text { assessment. Costs in } \\
2017 \text { pounds sterling } \\
(95 \% \mathrm{Cl})\end{array}$ & $\begin{array}{l}\text { Mean time and travel } \\
\text { costs in 2017 pounds } \\
\text { sterling }(95 \% \mathrm{CI})\end{array}$ & $\begin{array}{l}\text { Mean total cost to } \\
\text { individual in 2017 } \\
\text { pounds sterling }(95 \% \\
\mathrm{CI})\end{array}$ \\
\hline M0 & $229(158 ; 300)$ & $253(182 ; 325)$ & $482(348 ; 617)$ \\
\hline M6 & $160(97 ; 222)$ & $177(141 ; 212)$ & $336(260 ; 412)$ \\
\hline M12 & $159(97 ; 221)$ & $153(118 ; 187)$ & $312(233 ; 390)$ \\
\hline M18 & $109(59 ; 160)$ & $116(87 ; 144)$ & $225(166 ; 284)$ \\
\hline M24 & $102(71 ; 132)$ & $135(95 ; 175)$ & $237(178 ; 295)$ \\
\hline $\begin{array}{l}\text { Pooled } \\
\text { sample }\end{array}$ & $159(132 ; 186)$ & $174(153 ; 195)$ & $333(289 ; 377)$ \\
\hline
\end{tabular}


Table 3. Estimates from GLM regression models (log link function) of the difference in costs between low and high GCPS status.

\begin{tabular}{|c|c|c|c|}
\hline Variable & $\begin{array}{l}\text { Change in cost in } \\
2017 \text { pounds sterling } \\
(95 \% \mathrm{Cl})\end{array}$ & $\begin{array}{l}\text { Mean out-of-pocket } \\
\text { costs in Low GCPS } \\
\text { group in } 2017 \\
\text { pounds sterling } \\
(95 \% \mathrm{CI})\end{array}$ & $\begin{array}{l}\text { Mean out-of-pocket } \\
\text { costs in High GCPS } \\
\text { group in } 2017 \text { pounds } \\
\text { sterling }(95 \% \mathrm{Cl})\end{array}$ \\
\hline $\begin{array}{l}\text { Out-of-pocket costs } \\
\text { [Total of } 705 \text { observations: } \\
478 \text { in low GCPS; } 227 \text { in } \\
\text { high GCPS] }\end{array}$ & $\begin{array}{l}311 \\
(280 ; 342)\end{array}$ & $\begin{array}{l}240 \\
(230 ; 250)\end{array}$ & $\begin{array}{l}551 \\
(522 ; 581)\end{array}$ \\
\hline $\begin{array}{l}\text { Indirect costs } \\
\text { [Total of } 352 \text { observations: } \\
251 \text { in low GCPS; } 101 \text { in } \\
\text { high GCPS] }\end{array}$ & $\begin{array}{l}2312 \\
(1886 ; 2737)\end{array}$ & $\begin{array}{l}681 \\
(631 ; 730)\end{array}$ & $\begin{array}{l}2992 \\
(2575 ; 3410)\end{array}$ \\
\hline
\end{tabular}


Table 4. Mean Indirect costs per 6 month period

\begin{tabular}{|c|c|c|c|c|c|}
\hline Time point & \begin{tabular}{l|} 
Days \\
absent due \\
to POFP \\
(SD)
\end{tabular} & $\begin{array}{l}\text { Absenteeism cost } \\
\text { in } 2017 \text { pounds } \\
\text { sterling }(95 \% \mathrm{CI})\end{array}$ & $\begin{array}{l}\text { Days present } \\
\text { with POFP } \\
\text { (SD) }\end{array}$ & $\begin{array}{l}\text { Presenteeism cost } \\
\text { in } 2017 \text { pounds } \\
\text { sterling }(95 \% \mathrm{Cl})\end{array}$ & $\begin{array}{l}\text { Total } \\
\text { Employer cost } \\
\text { in } 2017 \\
\text { pounds } \\
\text { sterling }\end{array}$ \\
\hline $\mathrm{MO}(\mathrm{n}=97)$ & $3.0(8.2)$ & $308(112 ; 505)$ & $44.3(50.1)$ & $\begin{array}{l}1341(866 ; \\
1815)\end{array}$ & $\begin{array}{l}1649(1147 ; \\
2151)\end{array}$ \\
\hline M6 $(n=89)$ & $2.4(7.8)$ & $253(87 ; 418)$ & $36.8(43.7)$ & $\begin{array}{l}1455(851 ; \\
2058)\end{array}$ & $\begin{array}{l}1707(1113 ; \\
2301)\end{array}$ \\
\hline M12 $(n=80)$ & $0.6(1.5)$ & $60(25 ; 95)$ & $33.0(39.3)$ & $925(486 ; 1363)$ & $\begin{array}{l}985(538 ; \\
1432)\end{array}$ \\
\hline M18 $(n=66)$ & $0.6(1.5)$ & $62(24 ; 100)$ & $23.9(32.3)$ & $775(405 ; 1145)$ & $\begin{array}{l}837(444 ; \\
1231)\end{array}$ \\
\hline M24 $(n=63)$ & $1.2(4.1)$ & $119(13 ; 225)$ & $30.2(41.3)$ & $590(315 ; 865)$ & $\begin{array}{l}709(362 ; \\
1056)\end{array}$ \\
\hline $\begin{array}{l}\text { Pooled sample } \\
\text { (395 } \\
\text { observations) }\end{array}$ & $1.7(5.9)$ & $174(113 ; 236)$ & $34.6(42.9)$ & $\begin{array}{l}1068(849 ; \\
1287)\end{array}$ & $\begin{array}{l}1242(1014 ; \\
1470)\end{array}$ \\
\hline
\end{tabular}




\section{Appendices}

\section{List of Figures}

Figure 1 Extract from Use of Services and Productivity Questionnaire (USPQ) to give example of

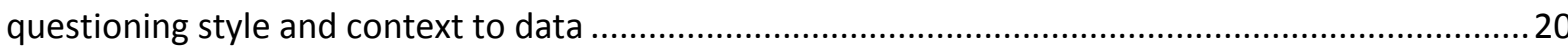

Figure 2 Extract from Time and Travel questionnaire to give example of questioning style and context to data

Figure 3 Work attendance with health problems scale (Van Roijen et al. 1996) - 395 observations

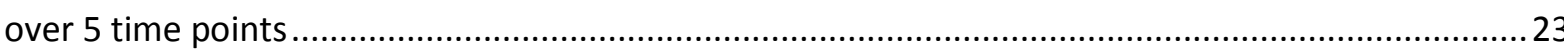

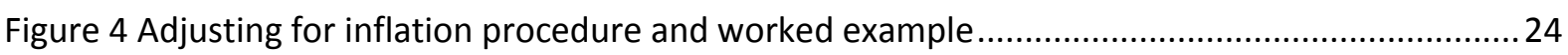

Figure 5 Worked example of a patient appointment unit cost for a patient attending their General

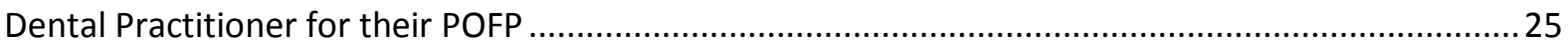

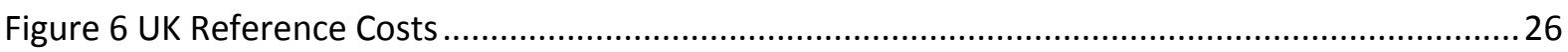

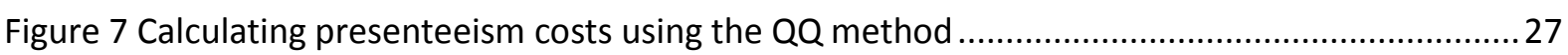

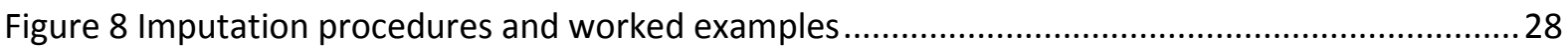

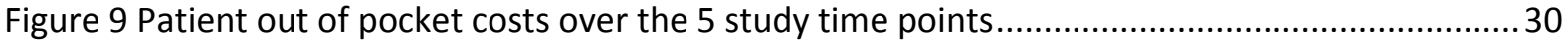

Figure 10 Employer indirect costs over the 5 study time points ................................................... 31

\section{List of tables}

Table 1 Recruitment location of those recruited at baseline ${ }^{1}$....

Table 2 Generalized Gamma Linear Regression Model (Log Link Function) of factors associated with out of pocket costs (705 observations over 5 time points)

Table 3 Patients reporting employment in the Use of Services and Productivity Questionnaire over the 5 time points.

Table 4 Generalized Gamma Linear Regression Model (Log Link Function) of factors associated with indirect costs (352 observations over 5 time points) 
Figure 1 Extract from Use of Services and Productivity Questionnaire (USPQ) to give example of questioning style and context to data

\section{SECTION 1: CONSULTATIONS IN LAST 6 MONTHS}

Over the last six months how many times have you visited the practitioners listed below and have you had to pay for the attendance? Please write the number of times in the relevant box below. Please give details of the hospital dental or medical specialties that you have visited for example: restorative dentistry, rheumatology etc. Please indicate if it was a private consultation ie paid for by yourself outside of the NHS. Please give the total private or NHS charges you had to pay for the consultation(s). Please do not include any prescription charges, just those for having the consultation.

\section{Question 1.2 Visits to a General Dental Practitioner}

Have you seen a general dentist? Yes $\square$ No (move to question 1.3)

If yes, did you see them as an NHS patient? Yes

No

How many times did you see the dentist?

If you had to pay anything for your dental appointments, how much have you paid in total over the last six months? 


\section{Figure 2 Extract from Time and Travel questionnaire to give example of questioning}

style and context to data

\section{Section 1 PATIENT TRAVEL COSTS}

This first part of the questionnaire asks about the costs of your travel and attendance at any of the following health care practitioners: General Medical Practitioner, General Dentist, Physiotherapist, Psychologist, Hospital dental specialist, Hospital medical specialist, Alternative therapy for example: chiropractor, osteopath, and acupuncturist.

\section{Question 1.1}

Have you ever visited any of the following healthcare practitioners regarding your pain in your mouth and or face? Please tick those that you have seen.

General Medical Practitioner

General Dentist

Physiotherapist

Psychologist

Hospital dental specialist

Please give details of the specialties seen:

Hospital medical specialist

Please give details of the specialties seen:

\section{Question 1.2}

Please complete parts A-H below for any practitioners you have indicated that you have seen in question 1.1 regarding your pain in your mouth and or face. Please give only one mode of transport per practitioner. If you have seen more than one practitioner with respect to your pain eg: 2 hospital specialists, put the additional details in part $\mathrm{h}$ "other".

\section{A) ATTENDANCE AT GENERAL MEDICAL PRACTITIONER:}

What was your normal mode of transport?

Walk/cycle

Ambulance/hospital car

Public transport (bus, train, metro)

Taxi

Private car/motorbike

Cost of one way fare $£$

Cost of one way fare $£$

How many miles was a one way trip?

What was your normal travelling time?

Travelling time $\square \square$ hrs: $\square \square$ mins

What was the normal time spent at the general medical practitioner's surgery?

Time spent at surgery $\square \square$ hrs: $\square \square$ mins 
Did someone normally go with you to your appointment?

No

Yes

If Yes, please indicate who normally went with you to the practitioner below. You may tick more than one box if appropriate:

Partner/spouse

Child/children under 16 years

Other relative

Paid caregiver

Other (please specify)

Details: 
Figure 3 Work attendance with health problems scale (Van Roijen et al. 1996) - 395 observations over 5 time points

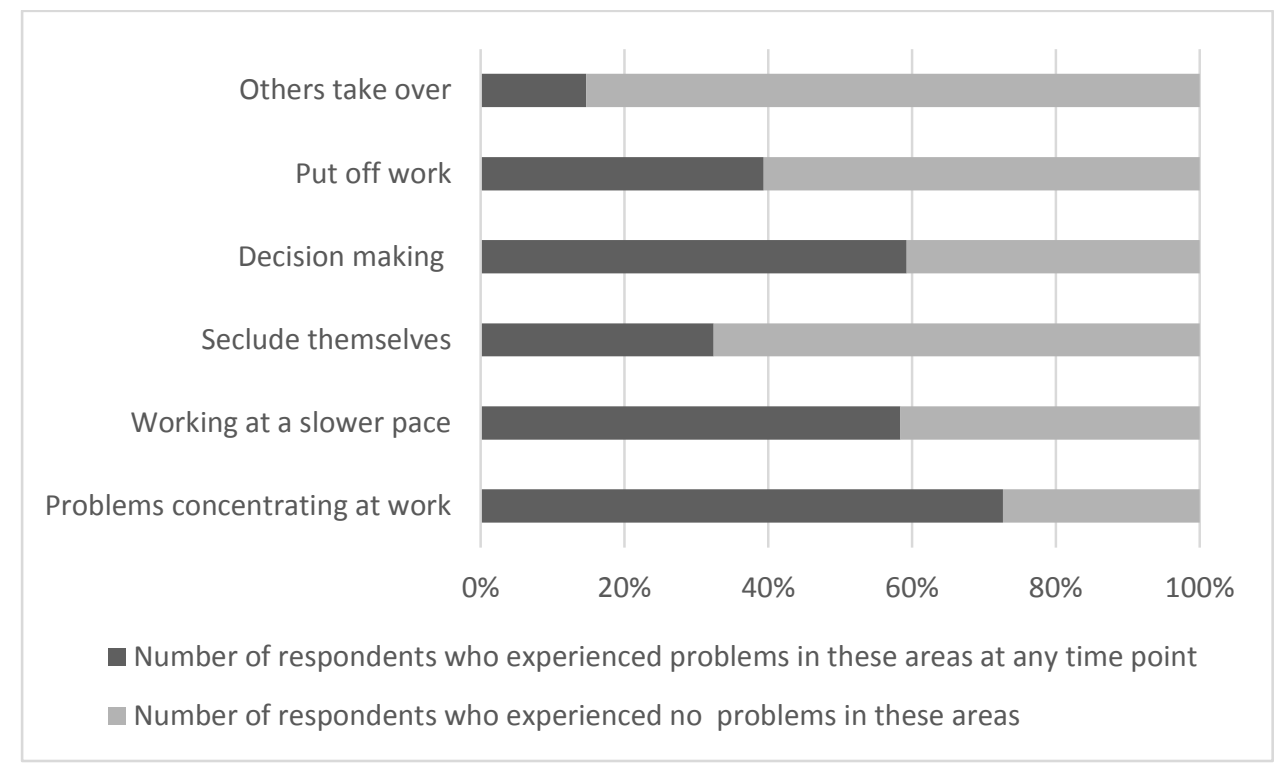

Problems experienced at work as a result of POFP were converted from a 4-point ordinal scale response indicating frequency of problems (almost never, sometimes, often, almost always) to a dichotomized format (i.e. never or ever experienced problems) and pooled to provide a cumulative frequency of the employed subsample who had ever experienced the individual problem. 


\section{Figure 4 Adjusting for inflation procedure and worked example}

Adjustment for inflation was applied so that all costs are given in 2012 prices. While calculation of many costs was based on 2012 reference costs (e.g. mileage rate, average income and valuation of leisure time) and adjustment for inflation was not necessary; other costs reported in questionnaires were comprised of actual expenditure e.g. public transport/taxi costs, out of pocket medication costs, consultation and treatment costs and therefore adjustment for inflation was required to convert these to 2012 prices. The adjustment for inflation method applied used Consumer Price Inflation from the Office for National Statistics (Office for National Statistics 2017) with the following rates of inflation:

\begin{tabular}{|l|l|}
\hline Year & CPIH \% change over 12 months \\
\hline 2013 & 2.3 \\
\hline 2014 & 1.5 \\
\hline 2015 & 0.4 \\
\hline 2016 & 1.0 \\
\hline 2017 & 2.6 \\
\hline
\end{tabular}

These were applied based on when an individual joined the study, for example if a patient joined the study in 2012 their M0 and M6 were considered to be in 2012 prices, their M12, M14 and M18 were considered to be in 2013 prices and their M24 questionnaire to be in 2014 prices. For example if this patient reported an out of pocket expenditure on over-thecounter medication of $£ 12$ in their M12 use of services questionnaire, this was considered to be in 2013 prices and to convert to 2012 prices the relevant adjustment was applied as follows:

$12 \times(1 / 1.023)=£ 11.73$

If the same individual, in their M24 questionnaire, reported expenditure on over-the-counter medication of $£ 18$, this was considered to be in 2014 prices and the following calculation was used to convert this to 2012 prices.

$18 \times(1 / 1.015) \times(1 / 1.023)=£ 17.34$ 
Figure 5 Worked example of a patient appointment unit cost for a patient attending their General Dental Practitioner for their POFP

Information provided by patient in time and travel questionnaire:

Normal mode of transport: Private car

Number of miles for one way trip: 6

Travelling time: 50 minutes

Time spent at surgery: 30 minutes

Accompanied to appointment: No

Was required to arrange childcare or care for dependents: No

Main activity if not attending appointment: Leisure activities

Cost calculation based on information provided above:

Travel cost:

6 miles $\times 2$ journeys (for return journey) $x £ 0.45$ (HMRC mileage allowance) $=£ 5.40$

Time cost:

50mins (travelling time) +30 mins (appointment time) $=80$ mins $=1.33$ hours

1.33hrs x £5.16 (U.K. Government's Department of Transport value hourly time value for non-working individuals) $=£ 6.86$

$\underline{\text { Total appointment cost to patient }=£ 5.40+£ 6.86=£ 12.26}$ 


\section{Figure 6 UK Reference Costs}

The following costs were used when calculating costs for patient time and travel:

- For private vehicles, the UK's Her Majesty's Revenue and Customs (HMRC) 2012 mileage rate of £0.45 per mile was used (HM Revenue \& Customs 2013).

- Leisure time was valued at $£ 5.16$ using the Department of Transport's hourly time value for non-working individuals (Department for Transport 2015).

- For the calculation of individual's daily and hourly wages; in a six month period there were considered to be 26 working weeks and therefore in a month there were 4.33 weeks.

- In the case of incomplete employment data, a 2012 average UK hourly wage of $£ 12.77$ was used (Office for National Statistics 2016). For the generation of an average daily wage a working day was considered to last $7.5 \mathrm{hrs}$. 


\section{Figure 7 Calculating presenteeism costs using the QQ method}

The QQ method, as described by Brouwer (Brouwer et al. 1999) was used to estimate the productivity loss using the quality and quantity data from the use of services and productivity questionnaire. Quality and Quantity were reported by respondents on a 0-10 scale where 10 was usual quality and 0 indicated very poor quality.

If a respondent who worked for $8 \mathrm{hrs}$ a day reported 7 out of 10 on the quantity scale and 6 out of 10 on the quality scale the calculation was as follows.

Quantity loss $(\mathrm{hrs})=(1-7 / 10) \times 8=2.4 \mathrm{hrs}$

Quality loss is calculated in the same manner, however before calculating the quality loss, the quantity loss is subtracted from the time worked i.e. we assume that the respondent worked the equivalent of 8-2.4 $=5.6 \mathrm{hrs}$.

Quality loss $(\mathrm{hrs})=(1-6 / 10) \times 5.6=2.24 \mathrm{hrs}$

The final $Q Q$ score is the sum of the quantity and quality loss calculated $=4.64 \mathrm{hrs}$ per day.

This value is multiplied by the number of days that the respondent reported working while experiencing pain and multiplied by their hourly rate of pay to estimate the total cost of presenteeism. 


\section{Figure 8 Imputation procedures and worked examples}

Management of this missing data was as follows:

Missing salary data were substituted by UK average values.

Missing time and travel data were not imputed at an item level as these were used to inform mean unit costs applied to patients with missing time and travel data (see example 1 below), However if a patient's partially complete data was greater than the mean unit cost value then this was used in preference to the mean unit cost.

Missing use of services and productivity data were assumed to be non-applicable where questions were left completely blank and hence a zero value was used. Where questions were partially completed (e.g. a respondent had indicated they incurred a cost but did not provide the amount) mean imputation was performed, at an item level. Median imputation was performed for categorical variables (those describing problems experienced at work).

\section{Example 1. Imputation using average unit cost}

A patient's total time and travel costs are the sum of the cost of their attendance at each of the healthcare professionals that they were asked about in the USPQ. If a patient had not provided information about a specific practitioner in the time and travel questionnaire then the average value of visits to that practitioner was used. For example, in their 18M USPQ, if a patient reported attending 3 GP appointments, 2 GDP appointments and 1 Physiotherapist appointment in the past in the previous 6 months, but had only provided time and travel information about their GDP ( $£ 3.60$ per appointment) and Physiotherapist ( $£ 10.80$ per appointment) in the Time and Travel questionnaire, then the mean value for a GP appointment (£11.62) was used. This patient's time and travel cost would be as follows:

Time and travel costs per 6 months at 18M:

= GP appointment cost x $3+$ GDP appointment cost $x 2+$ Physiotherapist appointment $x 1$

$=£ 11.62 \times 3+£ 3.60 \times 2+£ 10.80 \times 1$

$=£ 52.86$ per 6 month period.

Example 2. Imputation using average number of appointments

Similarly to the above example a patient may have indicated in their $14 \mathrm{M}$ month questionnaire that their time and travel costs for a GP visit was $£ 5.60$ and in their $12 \mathrm{M}$ questionnaire indicated that they had visited their GP in the previous 6 months but did not indicate how many times, this value was imputed using the mean number of GP appointments at that time point (4.4). Cost was then calculated using the imputed number of visits multiplied by the cost of their appointment.

$=£ 5.60 \times 4.4$

$=£ 24.64$

\section{Example 3. Imputation using average wage}

A patient's indirect costs (through absenteeism or presenteeism) are the sum of the time lost from work. If a patient had a QQ score (see calculation in Figure 5) of 4.64hrs per day, reported experiencing pain at work for 18 days in the previous 6 months, but had declined to provide income details in their CRF then the average UK average wage was used (£12.77): 
Presenteeism cost per 6 month period $=Q Q$ score $\mathrm{x}$ hourly wage $\mathrm{x}$ days worked while in pain.

$=4.64 \times £ 12.77 \times 18$

$=£ 1066.55$ presenteeism cost per 6 month period 
Figure 9 Patient out of pocket costs over the 5 study time points

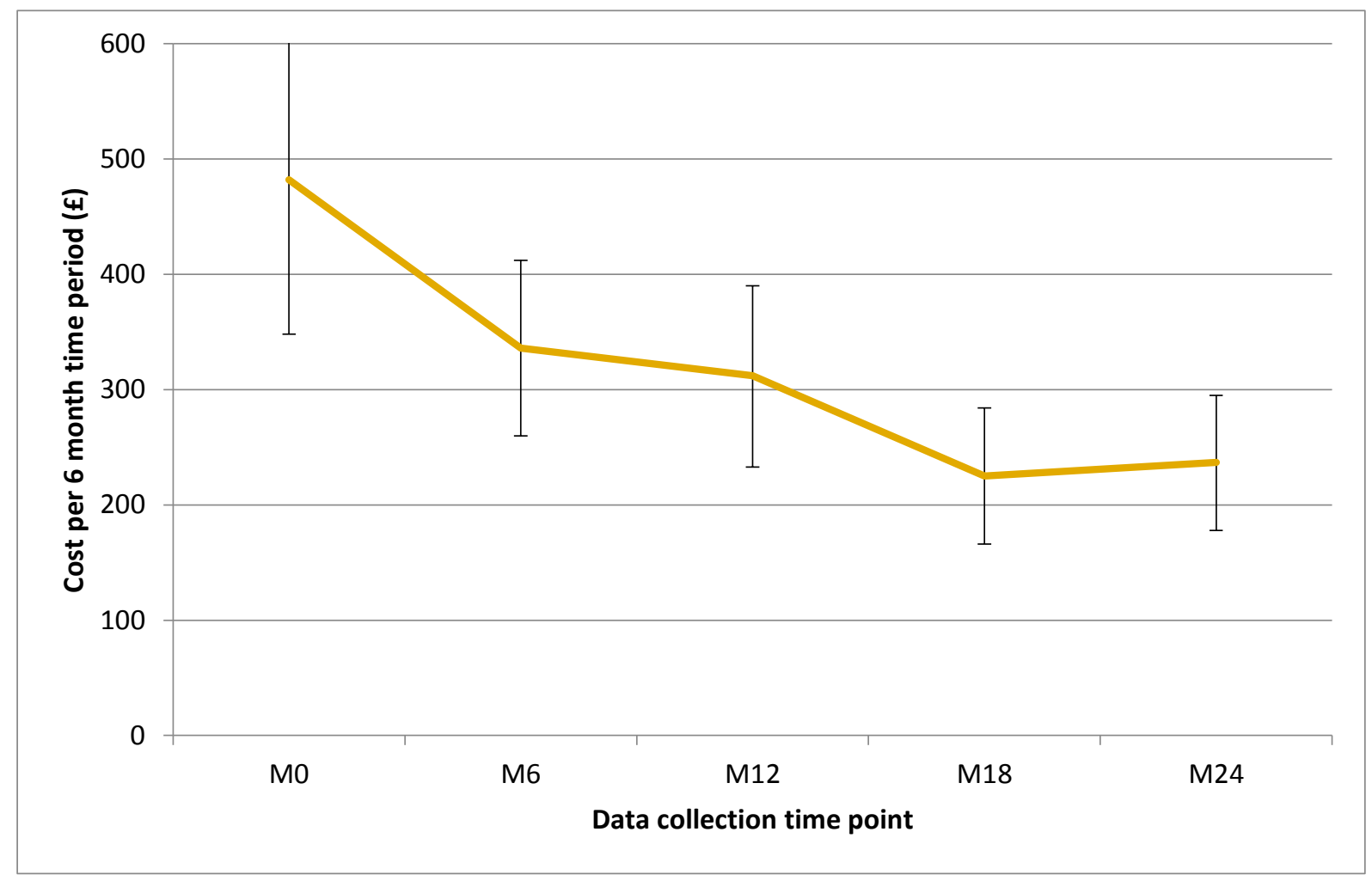

${ }^{*}$ A one way ANOVA and Bonferroni post-hoc test suggested significant differences between $M 0$ and M12, M18 and M24 costs: $(F(4,785)=4.90 ; p<0.01)$. Error bars represent $95 \%$ confidence interval of the mean cost at each time point. 
Figure 10 Employer indirect costs over the 5 study time points

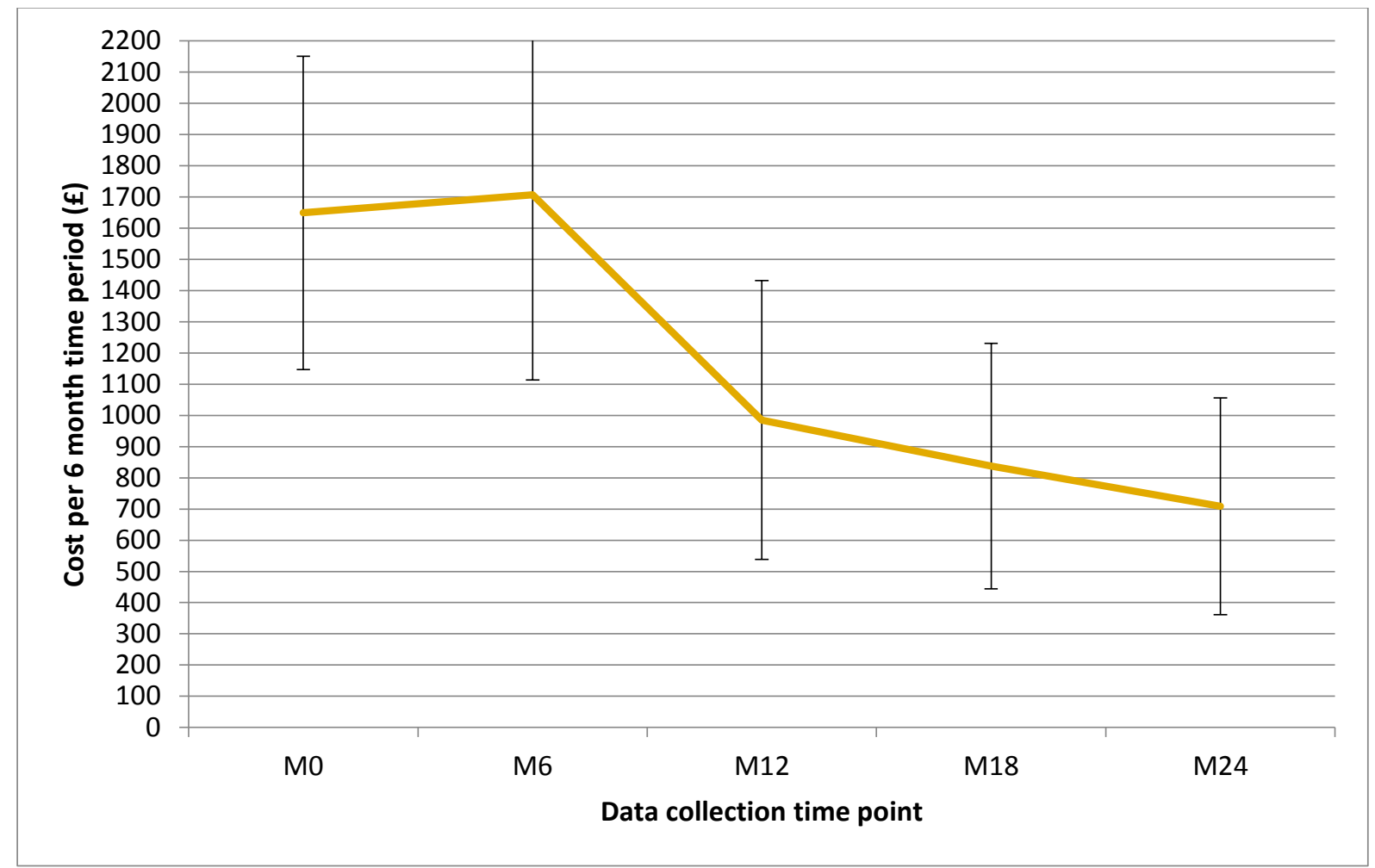

${ }^{*} \mathrm{~A}$ one way ANOVA and Bonferroni post-hoc test suggested significant differences between M6 and M24 costs: $(F(4,390)=3.42 p<0.01)$. Error bars represent $95 \%$ confidence interval of the mean cost at each time point. 
Table 1 Recruitment location of those recruited at baseline ${ }^{1}$

\begin{tabular}{|c|c|c|c|c|c|c|}
\hline \multirow[t]{2}{*}{ Recruitment location } & \multicolumn{2}{|c|}{ Recruited from clinic } & \multicolumn{2}{|c|}{$\begin{array}{l}\text { Recruited by } \\
\text { advertisement }{ }^{2}\end{array}$} & \multirow{2}{*}{$\begin{array}{l}\text { Total } \\
\mathrm{N}\end{array}$} & \multirow{2}{*}{$\begin{array}{l}\text { Total } \\
\%\end{array}$} \\
\hline & $\mathrm{N}$ & $\%$ & $\mathrm{~N}$ & $\%$ & & \\
\hline $\begin{array}{l}\text { General Medical } \\
\text { Practice }\end{array}$ & 49 & 24.3 & 21 & 58.3 & 70 & 29.4 \\
\hline $\begin{array}{l}\text { General Dental } \\
\text { Practice }\end{array}$ & 32 & 15.8 & 15 & 41.7 & 47 & 19.7 \\
\hline $\begin{array}{l}\text { Total primary } \\
\text { (community, non- } \\
\text { specialist) care }\end{array}$ & 81 & 40.1 & 36 & 100 & 117 & \\
\hline $\begin{array}{l}\text { Oral and Maxillofacial } \\
\text { Surgery }\end{array}$ & 40 & 19.8 & - & - & 40 & 16.8 \\
\hline Oral Medicine & 13 & 6.4 & - & - & 13 & 5.5 \\
\hline Neurology/surgery & 23 & 11.4 & - & - & 23 & 9.7 \\
\hline $\begin{array}{l}\text { Restorative dentistry } \\
\text { (Prosthodontics, } \\
\text { periodontics, } \\
\text { endodontics) }\end{array}$ & 45 & 22.3 & - & - & 45 & 18.9 \\
\hline $\begin{array}{l}\text { Total } \\
\text { secondary/tertiary } \\
\text { (specialist) care }\end{array}$ & 121 & 59.9 & 0 & 0 & 121 & \\
\hline Total of all patients & 202 & 100 & 36 & 100 & 238 & 100 \\
\hline
\end{tabular}

${ }^{1}$ The one individual who withdrew their data at M18 is not included in this table therefore total is 238 instead of 239

${ }^{2}$ The advertisement was placed in primary care locations, local student halls of residence, university leisure centers, a local museum and several local pharmacies. Patients were classified based on their reported most recent use of health services. 
Table 2 Generalized Gamma Linear Regression Model (Log Link Function) of factors associated with out of pocket costs (705 observations over 5 time points)

\begin{tabular}{|c|c|c|c|c|}
\hline \multirow{2}{*}{$\begin{array}{l}\text { Variable } \\
\text { Dichotomized GCPS* } \\
\text { state (low, } 0 \text { to Ila; } \\
\text { high, Ilb to IV) } \\
\text { (reference category: Low } \\
\text { GCPS) }\end{array}$} & \multirow[t]{2}{*}{ Coefficient } & \multicolumn{2}{|c|}{$\begin{array}{l}\text { 95\% Confidence } \\
\text { Interval }\end{array}$} & \multirow[t]{2}{*}{$p$ value } \\
\hline & & & & \\
\hline High GCPS & 0.78 & 0.57 & 0.99 & $<0.01$ \\
\hline \multicolumn{5}{|l|}{$\begin{array}{l}\text { Time point (reference } \\
\text { category: } 0 \mathrm{M} \text { ) }\end{array}$} \\
\hline $6 \mathrm{M}$ & -0.28 & -0.56 & -0.01 & 0.05 \\
\hline $12 \mathrm{M}$ & -0.36 & -0.64 & -0.08 & 0.01 \\
\hline $18 \mathrm{M}$ & -0.66 & -0.95 & -0.36 & $<0.01$ \\
\hline $24 \mathrm{M}$ & -0.53 & -0.83 & -0.22 & $<0.01$ \\
\hline \multicolumn{5}{|l|}{$\begin{array}{l}\text { Age Group, years } \\
\text { (reference category: } 20 \text { - } \\
\text { 29) }\end{array}$} \\
\hline $30-39$ & 0.11 & -0.35 & 0.58 & 0.63 \\
\hline $40-49$ & -0.11 & -0.56 & 0.34 & 0.64 \\
\hline $50-59$ & 0.03 & -0.42 & 0.49 & 0.88 \\
\hline $60-69$ & 0.55 & 0.10 & 1.00 & 0.02 \\
\hline $70-79$ & 0.27 & -0.23 & 0.77 & 0.29 \\
\hline $80-89$ & 0.93 & 0.20 & 1.65 & 0.01 \\
\hline \multicolumn{5}{|l|}{$\begin{array}{l}\text { Male (reference } \\
\text { category: female) }\end{array}$} \\
\hline Male & -0.16 & -0.43 & 0.11 & 0.25 \\
\hline \multicolumn{5}{|l|}{$\begin{array}{l}\text { Education (reference } \\
\text { category: no public } \\
\text { examinations) }\end{array}$} \\
\hline Secondary examinations & 0.38 & 0.05 & 0.72 & 0.02 \\
\hline Degree or higher & 0.41 & 0.08 & 0.75 & 0.02 \\
\hline \multicolumn{5}{|l|}{$\begin{array}{l}\text { Collapse IMD } \\
\text { Score(reference } \\
\text { category: bottom } 50 \% \text { ) }\end{array}$} \\
\hline Top $50 \%$ & -0.08 & -0.29 & 0.13 & 0.44 \\
\hline \multicolumn{5}{|l|}{$\begin{array}{l}\text { Diagnosis (reference } \\
\text { category: } \\
\text { musculoskeletal origin) }\end{array}$} \\
\hline Neuropathic/vascular & -0.36 & -0.59 & -0.13 & $<0.01$ \\
\hline Combined & 0.23 & -0.03 & 0.49 & 0.08 \\
\hline \multicolumn{5}{|l|}{$\begin{array}{l}\text { Duration of pain, years } \\
\text { (reference category: }<1 \\
\text { year) }\end{array}$} \\
\hline $1-4$ & 0.57 & 0.24 & 0.90 & $<0.01$ \\
\hline$\geq 5$ & 0.52 & 0.20 & 0.84 & $<0.01$ \\
\hline Constant & 4.79 & 4.16; & 5.42 & $<0.01$ \\
\hline
\end{tabular}

${ }^{*}$ Graded Chronic Pain Scale

${ }^{* *}$ Index of Multiple Deprivation 
Table 3 Patients reporting employment in the Use of Services and Productivity Questionnaire over the 5 time points

\begin{tabular}{|l|l|l|l|l|l|}
\hline Time point & M0 (n=198) & M6 (n=172) & M12 (n=155) & M18 (n=136) & M24 (n=129) \\
\hline $\begin{array}{l}\text { Number } \\
\text { reporting } \\
\text { being in } \\
\text { employment } \\
(\%)\end{array}$ & $97(48.99)$ & $89(51.74)$ & $80(51.61)$ & $66(48.53)$ & $63(48.84)$ \\
\hline
\end{tabular}


Table 4 Generalized Gamma Linear Regression Model (Log Link Function) of factors associated with indirect costs (352 observations over 5 time points)

\begin{tabular}{|c|c|c|c|c|}
\hline \multirow{2}{*}{$\begin{array}{l}\text { Variable } \\
\text { Dichotomized GCPS* } \\
\text { state (low, } 0 \text { to lla; } \\
\text { high, Ilb to IV) } \\
\text { (reference category: Low } \\
\text { GCPS) }\end{array}$} & \multirow[t]{2}{*}{ Coefficient } & \multicolumn{2}{|c|}{$\begin{array}{l}95 \% \text { Confidence } \\
\text { Interval }\end{array}$} & \multirow[t]{2}{*}{ P value } \\
\hline & & & & \\
\hline High GCPS & 1.21 & 0.73 & 1.69 & $<0.01$ \\
\hline \multicolumn{5}{|l|}{$\begin{array}{l}\text { Time point (reference } \\
\text { category: } 0 M \text { ) }\end{array}$} \\
\hline $6 \mathrm{M}$ & -0.14 & -0.71 & 0.44 & 0.64 \\
\hline $12 \mathrm{M}$ & -0.61 & -1.23 & 0.00 & 0.05 \\
\hline $18 \mathrm{M}$ & -0.28 & -0.94 & 0.38 & 0.41 \\
\hline $24 \mathrm{M}$ & -0.89 & -1.54 & -0.24 & 0.01 \\
\hline \multicolumn{5}{|l|}{$\begin{array}{l}\text { Age Group, years } \\
\text { (reference category: } 20 \text { - } \\
29 \text { ) }\end{array}$} \\
\hline $30-39$ & -0.27 & -1.08 & 0.54 & 0.51 \\
\hline $40-49$ & -0.15 & -0.98 & 0.68 & 0.72 \\
\hline $50-59$ & -0.20 & -0.99 & 0.59 & 0.62 \\
\hline $60-69$ & -1.65 & -2.62 & -0.68 & $<0.01$ \\
\hline \multicolumn{5}{|l|}{$\begin{array}{l}\text { Male (reference } \\
\text { category: female) }\end{array}$} \\
\hline Male & 0.52 & -0.10 & 1.13 & 0.10 \\
\hline \multicolumn{5}{|l|}{$\begin{array}{l}\text { Education (reference } \\
\text { category: no public } \\
\text { examinations) }\end{array}$} \\
\hline Secondary examinations & -0.81 & -1.97 & 0.35 & 0.17 \\
\hline Degree or higher & -0.86 & -2.05 & 0.33 & 0.16 \\
\hline \multicolumn{5}{|l|}{$\begin{array}{l}\text { Collapse IMD }{ }^{\star *} \text { Score } \\
\text { (reference category: } \\
\text { bottom } 50 \% \text { ) }\end{array}$} \\
\hline Top 50\% & 0.07 & -0.39 & 0.53 & 0.77 \\
\hline \multicolumn{5}{|l|}{$\begin{array}{l}\text { Diagnosis (reference } \\
\text { category: } \\
\text { musculoskeletal origin) }\end{array}$} \\
\hline Neuropathic/vascular & 0.05 & -0.44 & 0.54 & 0.85 \\
\hline Combined & 0.83 & 0.16 & 1.51 & 0.02 \\
\hline \multicolumn{5}{|l|}{$\begin{array}{l}\text { Duration of pain, years } \\
\text { (reference category: }<1 \\
\text { year) }\end{array}$} \\
\hline $1-4$ & 0.83 & 0.02 & 1.65 & 0.04 \\
\hline$\geq 5$ & 0.54 & -0.30 & 1.38 & 0.21 \\
\hline Constant & 6.93 & 5.58 & 8.28 & $<0.01$ \\
\hline
\end{tabular}

${ }^{*}$ Graded Chronic Pain Scale

**Index of Multiple Deprivation 


\section{References}

Brouwer WBF, Koopmanschap MA, Rutten FFH. 1999. Productivity losses without absence: Measurement validation and empirical evidence. Health Policy. 48(1):13-27.

Transport analysis guidance: Webtag. 2015. [accessed 2017 26th June].

https://www.gov.uk/guidance/transport-analysis-guidance-webtag.

Travel - mileage and fuel rates and allowances

2013. [accessed]. https://www.gov.uk/government/publications/rates-and-allowances-travelmileage-and-fuel-allowances/travel-mileage-and-fuel-rates-and-allowances\#approvedmileage-rates-from-tax-year-2011-to-2012-to-present-date.

Earnings and working hours. 2016. [accessed 2016 August 28th ]. https://www.ons.gov.uk/employmentandlabourmarket/peopleinwork/earningsandworkingh ours/datasets/allemployeesashetable1.

Source dataset: Consumer price inflation time series dataset (mm23). 2017. [accessed 2017 20th September 2017].

https://www.ons.gov.uk/economy/inflationandpriceindices/timeseries/1550/mm23. 